\section{Sosyal Araştırmalar ve Davranış Bilimleri Dergisi}

ISSN:2149-178X

Volume: 7 Issue: 14 Year: 2021

\title{
COVID-19 Pandemi Sürecinde Türkiye'de Çocuk Hakları ${ }^{1}$
}

\author{
Dr. Öğr. Üyesi Esma ESGİN GÜNDER \\ esma.esgin@cbu.edu.tr \\ Manisa Celal Bayar Üniversitesi \\ Salihli Meslek Yüksekokulu \\ ORCID: 0000-0002-5766-7194
}

\section{Özet}

Bu çalışma, Covid-19 pandemi sürecinde başta ailede olmak üzere toplumsal yapıda çocuk haklarının dikkate alınmasının önemini vurgulamayı amaçlamaktadır. Çocuklar, ebeveynler ve eğitimciler için yeni olan öğrenme - öğretme ortamları, uzaktan eğitim uygulamaları ile pandemi sürecinde tedbir amaçlı getirilen kısıtlamalar bireyler üzerinde strese yol açarken beraberinde ailede çocuk istismarına da neden olabilmektedir. Çocukların hastalıklardan ve tehlikelerden korunup, yaşama ve gelişim haklarının karşılanması açısından uzaktan eğitim uygulamaları faydalı ve elverişli bulunsa da çevirim içi derslere erişim olanağı bulamayan çocuklar için hak ihlallerine ve bazı gelişimsel sorunlara neden olmaktadır.

Pandemi sürecinde alınan tedbirlerden biri olan sosyal izolasyonun özellikle okul öncesi dönemdeki çocukların fiziksel aktiviteleri ile (oyun hakkı) akranlarıyla sosyalleşme becerilerini sınırlandırmasının yakın gelecekteki gelişimsel sonuçları da farklı çalışmalarda irdelenmektedir. Bu bağlamda bu çalışma, Covid-19 pandemi sürecinde alınan tedbirler ve geliştirilen uygulamalar çerçevesinde Türkiye'de çocuk haklarını, Çocuk Hakları Sözleşmesinin dört temel ilkesinden hareketle güncel araştırma ve rapor sonuçlarına dayalı olarak incelemeyi amaçlayan bir derlemedir.

\footnotetext{
$1 \mathrm{Bu}$ çalışma, yazar tarafından "X. Uluslararası Sosyal Araştırmalar ve Davranış Bilimleri (SADAB) Sempozyumu”nda sunulan özet bildiriden türetilmiştir.
} 
Anahtar Kelimeler: Covid-19 Pandemi , Çocuk Hakları, Aile, Sosyal İzolasyon, Okul Öncesi Dönem.

Jel Sinıflandırması : I18, K38, K36, O15, I29.

\title{
Children's Rights in Turkey During the COVID-19 Pandemic
}

\begin{abstract}
This study aims to emphasize the importance of considering children's rights in the social structure, especially in the family, during the Covid-19 pandemic process. Learning-teaching environments, which are new for children, parents and educators, distance education practices, and precautionary restrictions during the pandemic process cause stress on individuals and cause child abuse in the family. Although distance education applications are found useful and convenient in terms of protecting children from diseases and dangers and meeting their right to life and development, they cause violations of rights and some developmental problems for children who cannot access online courses.
\end{abstract}

The near-future developmental consequences of social isolation, which is one of the measures taken during the pandemic process, especially when pre-school children's physical activities (the right to play) and their ability to socialize with their peers are examined in different studies. In this context, this study is a compilation that aims to examine children's rights in Turkey, based on the results of current research and reports, based on the four basic principles of the Convention on the Rights of the Child, within the framework of the measures taken and practices developed during the Covid-19 pandemic.

Keywords: Children's Rights, Pandemic Covid-19, Family, Social Isolation, Preschool Children. Jel Codes : I18, K38, K36, O15, I29. 


\section{GİRIŞ}

Covid-19 pandemi süreci tüm dünyada yalnızca sağlık alanında değil, sosyal ve psikolojik "iyi olma hali" üzerinde de ciddi bir tehdit oluşturmaktadır. Yayılım hızındaki artışla birlikte küresel bir sağlık ve toplumsal sorun haline dönüşen Covid-19 pandemisi özellikle fiziksel ve sosyal mesafeyle birlikte başta yaşam alanlarının sınırlandırılması, üretimde daralmayla birlikte yaşanan ekonomik sorunlar, işsizlik oranlarındaki artış, eğitim hizmetlerine erişimde yaşanan yetersizlikleri ile aile içinde yaşanan şiddet vakalarındaki artışlarla çoklu görünüme sahiptir.

Pandeminin beraberinde getirdiği risklerle birlikte bu süreçte yaşanan sorunların yayılımını azaltmak ve önüne geçebilmek için pek çok ülkede fiziksel ve sosyal mesafe ile birlikte sosyal izolasyon düzenlemelerine gidilmiştir. Ancak, tedbir amacıyla yapılan bu düzenlemeler de gerek okul öncesi dönem gerekse de okul çağı çocuklarının bedensel, bilişsel, sosyal ve duygusal gelişimlerinde olumsuzluklara yol açarken çocuk hakları ihlallerine neden olabilmektedir.

$\mathrm{Bu}$ bağlamda bu çalışmada, Covid-19 pandemi sürecinde alınan tedbirler ve geliştirilen uygulamalar çerçevesinde Türkiye'de çocuk haklarını, Çocuk Hakları Sözleşmesinin dört temel ilkesinden hareketle güncel araştırma ve rapor sonuçlarına dayalı olarak irdelenmesi amaçlanmaktadır.

\section{Pandemi Süreci}

Aralık 2019'un sonlarında, Çin'in Hubei eyaletinin Wuhan şehrinde ortaya çıkan hızlı bulaş ve yayılma özelliği ile ölümcül etkileşim gösteren Coronavirüs (Covid-19) tüm dünyada toplumsal hayatı sınırlayan zorunlu bir karantina temelli yeni hayat şekli ortaya çıkarmıştır. Dünya Sağlık Örgütü (DSÖ) başkanı Tedros Adhanom Ghebreyesus, 31 Aralık 2019 tarihinde Covid-19 kodlamasının açılımını; belirli bir bölgeyi, canlı türünü ya da insanı etiketlemekten kaçınmak üzere "korona" için "CO", "virüs" için "VI", "hastalık" için "D” şeklinde tanımlamıştır. Coronavirüs'ün Çin'in ardından başta Asya bölge ülkeleri olmak üzere kısa sürede birçok ülkeye yayılarak tüm dünyayı etkilemesi ve uluslararası bir boyuta ulaşılmasıyla 30 Ocak 2020 tarihinde 
DSÖ, Covid-19'u uluslararası halk sağlığı sorunu kabul ederek pandemi ilan etmiştir (TÜBA,2020).

$\mathrm{Bu}$ sürecin ne zaman sona ereceğine dair net bir veri ya da öngörü bulunmamakla birlikte her gün ülkemizde ve dünyanın farklı ülkelerinde gözlenen bulaş ve vefat sayılarını içeren istatistiksel veriler ile gücünü pekiştirmektedir. Alınan tedbirler ve getirilen kısıtlamalarla halk sağlığını korumayı amaçlayan pandemi sürecinde toplumlar ve bireyler sosyolojik ve psikolojik bir dönüşümü yaşamaktadırlar. Arslan ve Karagül'e (2020:3) göre günlük yaşam pratikleri ile birlikte çalışma hayatının düzenini, eğitim - öğretim yöntemlerini değiştiren; ulaşım, turizm ve hizmet sektörü başta olmak üzere ekonomik büyüme ve istihdam politikalarını ciddi oranda olumsuz etkileyeceği öngörülen COVID-19 salgını, önümüzdeki dönemde birey-devlet ve uluslararası düzeyde değişimin başlatıcısı/hızlandırıcısı olabileceği düşünülmektedir.

Dünya Sağlık Örgütü başkanı Ghebreyesus, (BBC, 2020) pandemi sürecinin seyrini değiştirmenin ülkelerin elinde olduğunu belirtirken; "Her ülke kamu sağlı̆ıııı korumak ile ekonomik ve sosyal faaliyetlere yönelik kısıtlamaları en az seviyede tutmak arasında hassas bir denge bulmalı, bunları yaparken insan haklarına da saygılı olmalı." sözlerine yer vermiştir. Bu açıklamaya göre her ülkenin halkını bilgilendirme ve risklerden koruma sorumluluğu vardır. Ancak, bazı ülkeler bu sorumluluğu yerine getirecek, yeterli önlemi alacak kaynaklara sahip değildir.

\section{3. Çocuk Hakları}

Birleşmiş Milletlerin, İnsan Hakları Evrensel Bildirisinde çocukların özel bakım ve yardıma hakkı olduğunu ilân ettiği 20 Kasım 1989 tarihinde imzalanan "Çocuk Haklarına Dair Sözleşme" (ÇHS) Türkiye'nin de bulunduğu tüm taraf devletleri bağlayıcı elli dört maddeden oluşmaktadır (UNICEFTURK, 2021a). Sözleşme'de düzenlenen haklar yetişkinlerin haklarına çok benzese de, söz konusu sözleşme çocuk haklarının "özel" olduğuna vurgu yapmaktadır. Başta hükümetler olmak üzere toplumdaki tüm yetişkinler çocukların tüm haklarına erişimlerini sağlamak konusunda ek sorumluluklara sahiptir. Çünkü çocuklar büyüyor, öğreniyor ve bazen de yaşları nedeniyle daha fazla korunmaya ihtiyaç duyuyorlar (UNICEFTURK, 2021b). 
Çocukların korunmasından, farklı gelişim alanlarının desteklenmesine, ailenin güçlendirilmesinden özel ilgiye ve bakıma gereksinim duyan çocukların korunmasına kadar birçok önemli içeriğe sahip olan Çocuk Hakları Sözleşmesi dört temel ilke üzerine kuruludur. Yol gösterici olduğu gibi aynı zamanda çocuk haklarının tümünün yerine getirilmesi için temel gereklilikleri ifade eden bu ilkeler (UNICEFTURK, 2021c) :

Ayrımcılık yapmama: ÇHS'nin 42 maddesi dinleri, ırkları veya yetenekleri ne olursa olsun; ne düşündükleri veya söyledikleri gözetilmeksizin; kültürleri ne olursa olsun; kız veya erkek, zengin veya fakir fark etmeksizin TÜM çocukların haklarına ilişkindir.

Çocuğun üstün yararı: Çocukları etkileyebilecek yönde verilen her karar veya yapılan her işlem her zaman için onların üstün yararına öncelik tanımalıdır.

Çocuğun varlığını ve gelişimini sürdürmesini sağlama: Her çocuğun doğal olarak yaşama hakkı vardır. Onlara gelişmeleri ve potansiyellerini gerçekleştirebilmeleri için her firsatın temin edilmesi, karar verme yetkisine sahip bireylerin sorumluluğundadır.

Katılım: Çocuklar kendi yaşam ve tecrübelerinin uzmanlarıdır ve kendilerini etkileyecek kararlarda onlara danışılması gerekmektedir. Her çocuğun kendi düşüncesini ifade etme hakkı vardır ve haklarının en iyi şekilde nasıl korunacağı ve yerine getirileceğine ilişkin tavsiye ve değerli bilgiler verebilirler.

\section{Pandemi Sürecinde Türkiye'de Alınan Tedbirler ve Çocuk Hakları}

Yayılım hızındaki artışla küresel krizi kaçınılmaz kılan Covid-19 (Koronavirüs) Pandemi süreci, birey ve toplumlar için yalnızca sağlık açısından bir tehdit oluşturmamakta sosyal, ekonomik, kültürel ve psikolojik pek çok boyutta toplumsal hayatı etkilemektedir. Bu süreçte Çocuklar, Covıd-19 salgınının mağdurları gibi görünmeseler de salgının en büyük mağduru olma tehlikesi ile karşı karşıyalar. Covıd-19 salgını, çocukların sağlığı üzerinde, bildiğimiz kadarıyla en azından bugüne kadar, büyük bir etki yaratmasa da kriz, çocukların esenliğini ciddi ölçüde etkilemektedir (Sivilsayfalar, 2020). 
UNICEF (2021)'in "Covıd-19 Salgınının Çocuklar Üzerindeki Etkileri"ni konu edindiği yayınına göre tüm ülkelerde her yaştan çocuk, gerek pandemiden (doğrudan virüsün buluşması) gerekse pandeminin etkileri karşısında alınan tedbirlerden ve Sürdürülebilir Kalkınma Hedeflerini uygulama sürecindeki gecikmenin uzun vadedeki olası sonuçlarından etkilenmektedir.

Çalışmanın ilerleyen bölümünde pandemi sürecinde alınan tedbirlerin Türkiye'de Çocuk Haklarının uygulanışı ve varsa ihlalleri ve / veya ihmalleri dört temel ilke çerçevesinde irdelenecektir.

\subsection{Ayrım Gözetmeme ve Eğitim Hakkı}

Türkiye'de tüm kademelerde okullar ilk aşamada 16 Mart 2020 tarihinden 30 Nisan 2020 tarihine kadar tatil edilmiş, ilköğretim ve ortaöğretim düzeyinde açık ve uzaktan eğitim uygulamaları kapsamında 3 TV Kanalı ve Eğitim Bilişim Ağı (EBA) üzerinden eğitimlerin sürdürülmesine karar verilmiştir (MEB, 2020). Demirkaya (2021:133)'ya göre alınan bu kararla COVID-19 pandemi sürecinde çocukların eğitim hakkı için önemli olan, düzenli bir şekilde okula devamın sağlanması durumu özellikle ihmal edilmiştir. Anasınıfı, 8. ve 12. sınıflar dışında 2019-2020 2.dönem ve 2020-2021 1. ve 2. Dönem eğitim-öğretim y1lında toplam 30 gün kadar okula giden bir grup vardır. Yine, eğitim ihtiyacı olan ve uzaktan desteklenmesi de mümkün olmayan özel gereksinimli çocuklar ise göz ardı edilmiştir. Köy okulları öğrencileri yine mağdur gruplar arasındadır. Her ne kadar çevrimiçi uzaktan ders sistemiyle eğitim verilmekte olsa da Çocuk Hakları Sözleşmesi’nde okulun açık tutulmasının önemi özellikle vurgulanmıştır.

Bilişim Teknolojilerine erişim, internet altyapısı gibi faktörler göz önünde bulundurulduğunda eğitim alanında alınan bu tedbirlerin eğitim sistemindeki eşitsizlikleri arttırabileceği ve çocukların gelecekte, bugün kaçırdıkları öğrenme firsatları nedeniyle eğitimden uzaklaşma, işsizlik ve sosyal izolasyon gibi pek çok toplumsal sorunla ve tehditle karşı karşıya kalacağı düşünülmektedir.

Benzer şekilde Chang ve Satako (2020) da pandemi sürecinde uzaktan eğitim uygulamalarının öğrenciler arasında eğitim teknolojilerine erişimde yaşayabilecekleri yetersizlerin yanı sıra; özellikle dezavantajlı çevrelerde yaşayan çocukların sağlıklı / düzenli beslenme ve sağlık taramalarından mahrum kalması ile bu sürecinde ebeveynlere ve hatta öğretmenlere yük 
getireceğini, ev dışında sosyalleşme ortamı bulamayan çocuklarda sosyal izolasyonun yaşanabileceğine dikkat çekmektedirler.

\section{2. Çocuğun Yüksek Yararı}

Pandemi sürecindeki bulaşı riskinin yanı sıra çocukların bu süreçle ilgili yeterince bilgilendirilmeyişi, sosyal mesafe, arkadaşlarla etkileşim kuramama, ev ortamında kişisel alan yetersizliği ile ailenin yaşayabileceği ekonomik sorunlarla çocuklar bu süreçte strese maruz kalmakta ve kaygı durum bozuklukları yaşamaktadır (Wang and et al,2020:946). Yaşanan stres, çocukların yalnızca bedensel gelişimlerinde değil, bilişsel ve sosyal gelişimlerinde de yetersizliklere ve sorunlara yol açmaktadır.

Çocuklar, yetişkinlere kıyasla kendi gelişimsel, sosyal duygusal ve davranışsal gereksinimlerini bağımsız bir şekilde karşılayabilecekleri kaynaklara erişim konusunda deneyim ve beceri eksiklikleri yaşadıklarından pandemi gibi travmatik olaylardan önemli ölçüde etkilenen grupların başında gelmektedir (Akoğlu \& Karaaslan,2020:100).

Humphreys ve arkadaşları (2020) Covid-19 süreci boyunca inceledikleri çocuk ihmal ve istismar vakalarının özellikle ebeveynler arasındaki şiddet ile birlikte tırmanışa geçtiğini belirtmişlerdir. Çocukların aile içinde gerek doğrudan maruz kalmaları gerekse görsel ya da işitsel olarak bu sürece tanık olmaları çocuklarda alt ıslatma, tırnak yeme gibi çeşitli davranış bozukluklarına ve travma sonrası stres bozukluklarına yol açmaktadır.

Pandemi sürecinde "evde kal"ma sürecinin başta kadına yönelik şiddet olmak üzere aile içi şiddeti arttırdığı İstanbul Barosu Çocuk Hakları Merkezi tarafından ifade edilmektedir. İstanbul Barosu'ndan yapılan açıklamaya göre,Türkiye'de yeni tip Koronavirüs salgını döneminde 178 çocuk istismarı vakası için avukat görevlendirilmiştir. "Pandemi ilanından günümüze kadar İstanbul Barosu tarafindan çocuk haklarını ilgilendiren vakalar için yapılan avukat görevlendirmelerinde ciddi bir değişim gözlemlenmiştir. 10 Mart-20 Nisan 2020 arasında (son 41

günde) çocuğun cinsel istismarı suçu mă̆duru 178 çocuğa karakol aşamasında avukat görevlendirilmesi yapılmıştır. Buna karşıllı 1 Şubat-10 Mart 2020 arasında (pandemi ilân edilmeden önceki 38 günde) cinsel istismar mă̆duru 464 çocuk için avukat görevlendirmesi 
yapılmıştır." (İstanbul Barosu Çocuk Hakları Merkezi 23 Nisan 2020). Gerek önceki dönem gerekse de yıllar arası yapılan karşılaştırmalar mağdur çocuk sayısındaki azalmanın arkasında yatan sebeplerin dikkatle incelenmesi gerektiğine dair bir uyarıdır. Mağdur çocuk sayısında görülen sayısal azalmanın başlıca nedeninin pandemi sürecinde çocukların koruyucu mekanizmalara erişim konusunda sıkıntılar yaşadıkları düşünülmektedir.

\subsection{Yaşama ve Gelişme Hakkı}

ÇHS'nin temel ilkelerinden biri olan yaşama ve gelişme hakkı çerçevesinde çocukların okul öncesinden başlayarak yükseköğrenime kadar öğrenim gördükleri okullar yalnızca akademik becerilerin kazanılmasında değil, aynı zamanda yetişkin hayatına ve sorumluluklarına hazırlandıkları, toplumsal kuralları içselleştirdikleri, arkadaş gruplarında sosyalleştikleri önemli sosyal çevrelerdir (Hyde,2020:444). Pandemi sürecinde uzaktan eğitim uygulamaları ile her ne kadar çocukların akademik, eğitimsel ihtiyaçları karşılanmaya çalışılsa da sosyal mesafe ve sosyal izolasyon nedeniyle sosyal ve duygusal iyi olma hâli tam olarak sağlanamamakta çocuklarda strese dayalı davranış sorunları gözlenmektedir.

Çocukların yaşama ve gelişme hakkı önünde yaşanan bir diğer güçlük ise ekonomik yetersizlikler ve yoksulluktur. Pandemi sürecinde tırmanan yoksulluk oranının yine en çok çocukları etkileyeceği düşünülebilir. Açlık ve yetersiz beslenmenin yanı sıra iş kaybı yaşayan ebeveynlerle birlikte geçici ve süreksiz işlerde çalışmak zorunda bırakılan çocuklarla bu tehdit daha da artmaktadır.

Türkiye, çocuk yoksulluğu oranının \%25 ile (Güney Afrika ve Kosta Rika'dan sonra) en yüksek olduğu OECD ülkelerinden biridir. Pandemi süresince, sahada çalışan STK'ların yaptıkları görüşmeler, iş kayıplarına uğrayan ailelerin kiralarını ve faturalarını düzenli ödeyemedikleri, temel ihtiyaçları olan gıda erişimine dahi ulaşmakta zorlandıklarını göstermektedir. Çocuklar için ailenin maddi yoksunluğundaki artış, beslenme yetersizliği, gelecek kaygısının artması, psikolojik travmalar gibi çocukların iyi olma hallerini belirleyen birçok zorluğu barındırmaktadır (Akkan,2020:2). 


\subsection{Katılım Hakkı}

Gelişim özelliklerinden dolayı salgın sürecini anlama ve kavramada güçlükler yaşayan çocuklar bu süreçte ebeveynlerinin bilgilendirici tanımlamalarına ve duygusal desteklerine ihtiyaç duymaktadırlar. Bu durum ise ebeveynleri zorlamaktadır. Yeni düzene alışmaya çalışan annebabalar, ekonomik kayıpların, sağlık sorunlarının ve virüs riskinin somut etkilerini yaşarken bu süreci çocuklarına anlatma ve anlamlandırmada güçlükler yaşayabilmektedirler. Pandemi sürecinde alınan tedbirler çerçevesinde uygulanan sokağa çıkma yasağı / kısıtlaması ile oyun alanlarından, parklardan yoksun kalan çocukların bu durumda ebeveynlerine verdikleri tepkiler de yıkıcı olabilmektedir. Pandemi süreciyle ilgili ailede yetersiz bilgi paylaşımı, Koronovirüs'le ilgili yüksek kaygı ve artan ekonomik sıkıntılar ebeveynleri çocuklarına karşı anlayışsız ve tahammülsüz kılabilmekte bu durum da çocuğun ihmal ve istismarına neden olmaktadır.

Katılım hakkının yerine getirilmesi açısından çocuk hakları ihlalleri de yaşandığı bir diğer durum ve ortam ise çevirim içi derslerdir. Pandemi sürecinde, devletler okul öncesi eğitimden başlayarak yükseköğretime kadar çocukların evde çevrimiçi bir sistemde katılabilecekleri sanal sınıf uygulamaları geliştirmişlerdir. Ne var ki bu eğitim uygulamalarına katılım dijital bir alt yapı gerektirdiği için bilişim teknolojilerine sahip olmayan çocukların bu uygulamalara katılımı sağlanamamakta, çocuklar bu platformlarda seslerini duyuramamaktadırlar.

Derin Yoksulluk Ağ1 (2020), yapmış olduğu araştırmada, 103 haneden 73'ündeki okula giden 141 çocuğun \%57'sinin okullarda uzaktan eğitime geçilmesinden sonra dersleri takip edemediğini belirlemiştir. Çalışmada çocukların uzaktan eğitime devam edememe gerekçeleri ise \%60'ının tablet, bilgisayar ya da televizyonun olmaması, \%54'ünün internet bağlantısının olmaması, \%45'inin kendisini takip eden bir yetişkin olmaması, \%39'unun yeterli bilgiye sahip olmaması, \%18'inin isteksizlik ve \%7'sinin de çalışmak zorunda olması şeklinde sıralanmaktadır. Evde okur yazarlığın yanı sıra dijital okuryazarlığı olan bir ebeveynin olmadığı durumlarda da çocuklar uzaktan eğitime katılmakta zorluk çekmişlerdir. 


\section{Sonuç ve Öneriler}

21. yüzyılın en önemli sağlık ve toplumsal sorunu olan Covid-19 pandemi sürecinde, Türkiye'de çocuk hakları çerçevesinde haklara erişim sağlanmasında sekiz maddede güçlükler yaşanmaktadır. Bu maddeler sirasiyla :

Madde 6 : Yaşama, hayatta kalma ve gelişme hakkı,

Madde 17 : Zamanında, doğru ve anlaşılır bilgi ve medyaya erişim hakkı,

Madde 24 : Sağlık bakımı hizmetlerine erişim hakkı,

$>$ Madde 27 : Yeterli yaşama standardı ve bütünsel gelişim hakkı,

Madde 28 - 29 - 30 : Eğitime erişim hakkı,

Madde 31 : Dinlenme, boş zaman değerlendirme, oynama ve yaşına uygun eğlence (etkinliklerinde) bulunma ve kültürel ve sanatsal yaşama katılım hakk1.

Çocuk haklarına erişim sağlanmasında yaşanan bu güçlükler beraberinde; aile içi şiddet, toplumsal cinsiyet eşitsizliği, eğitime erişememe ve yoksulluk risklerini de beraberinde getirmektedir. Covid19 pandemisinin ciddi bir ekonomik krizi, işsizliği ve bununla ilişkili olarak yoksullaşmayı beraberinde getireceği öngörülmektedir. Ebeveynin işsiz kalması ve okuldan / eğitimden uzak kalma aynı zamanda çocuk işçiliğinin de önünü açabileceği için bu durum, çocukların daha kırılgan özneler haline gelmesine sebep olabilir.

Avrupa Konseyi (COE, 1996) tarafından yayımlanan Çocuk Hakları Stratejisi Belgesinde; 2021 yılı ve sonrasında çocuk haklarının teminat altın alınmasında ulusal, bölgesel ve yerel yönetimler ile sadece hükümetlerin değil özel sektörün ve hatta uluslararası kuruluşların tek paydada toplanacağı büyük organizasyonlara vurgu yapılmaktadır.

Bu bağlamda Covid-19 pandemisinin Türkiye'de çocukları özellikle de kırılgan çocukları (mülteci çocuklar, yoksul çocuklar, engelli çocuklar) etkileyen boyutları hakkında daha fazla bilgi toplanarak, etkinin niteliğinin somut verilerle paylaşılması gerektiği düşünülmektedir.

Covid-19 pandemisi küresel bir sağlık krizi olduğu için gerçekleştirilecek "çocuk" odaklı çalışmalarda çok ortaklı çalışmalar yapılabilir. Çocukların başta beslenme ve sağlık ihtiyaçlarının karşılanmasında ve eğitim süreçlerine katılımlarında yüksek yararını gözetecek, yaşama ve gelişim 
hakkını destekleyecek girişimlerde yerel yönetimler ile Sanayi ve Ticaret Odaları ve özel sektörün yanı sıra uluslararası organizasyonların (UNICEF gibi) bir arada eşgüdümlü çalışması gerekmektedir.

Gerek pandemi süresince gerekse de pandemi sonrasında çocukların bedensel, bilişsel, sosyal ve duygusal iyi olma hâlini korumak ve güvence altına almak için Çocuk Hakları Sözleşmesinin uygulanmasından sorumlu kurum olan Aile ve Sosyal Hizmetler Bakanlığımız çocuk haklarının gözetilmesiyle ilgili yol haritası belirleyerek ek önlemler almalıdır.

\section{Kaynakça}

AKKAN, B. (2020). Kovid-19'un Çocuklar Üzerinde Etkisi ve Çocuk Odaklı Sosyal Politikalar, TESEV Değerlendirme Notlarl, 2020/6. https://www.tesev.org.tr/wpcontent/uploads/TESEV_Kovid19_Cocuklar_Uzerinde_Etkisi_Basak_Akkan.pdf (12.09.2021) AKOĞLU, G.,KARAASLAN, B.T. (2020). "COVID-19 ve İzolasyon Sürecinin Çocuklar Üzerindeki Olası Psikososyal Etkileri", İzmir Kâtip Çelebi Üniversitesi Sağlık Bilimleri Fakültesi Dergisi 2020; 5(2): 99-103.

ARSLAN, İ., KARAGÜL,S. (2020) "Küresel Bir Tehdit (COVID-19 Salgını) ve Değişime Yolculuk", Üsküdar Üniversitesi Sosyal Bilimler Dergisi, sayı: 10, (Mayıs 2020): 1-36, http://doi.org/10.32739/uskudarsbd.6.10.67

BBC. "Pandemi nedir, ülkeleri nasıl etkiler? - Dünya Sağlık Örgütü Koronavirüsü Pandemi İlan Etti.” 12.Mart.2020 https://www.bbc.com/turkce/haberler-dunya$51614548(21.07 .2021)$

CHANG, G.C. , SATAKO, Y.(2020). How are countries addressing the Covid-19 challenges in education? A snapshot of policy measures. https://gemreportunesco.wordpress.com/2020/03/24/how-are-countries-addressing-thecovid-19-challenges-in-education-a-snapshot-of-policy-measures/, Erişim Tarihi: 12.09.2021.

COE (2020). https://rm.coe.int/avrupa-konseyi-cocuk-haklar-stratejisi-2016-2021-/1680931c9b Erişim Tarihi: 12.07.2021. 
COE (2020). COVID-19 Pandemic Responses - Lessons Learnt From Management and Adaptation to Ensure That Children are Treated as Rights Holders During the Pandemic and Beyond. Summary Report, https://rm.coe.int/final-summary-report-covid-19-pandemicresponses/16809f8032 Erişim Tarihi: 04.06.2021.

DEMİRKAYA, S.K. (2021). "Pandemi ve Çocuğa Yönelik Ayrımcılık - Okul Kapatma: Bir Çocuk Haklar1 İhlali", $\quad$ Klinik $\quad$ Psikiyatri, 24:133-134. https://jag.journalagent.com/kpd/pdfs/KPD_24_2_133_134.pdf Erişim Tarihi: 08.09.2021.

DERIN YOKSULLUK AĞI (2020). Pandemi Döneminde Derin Yoksulluk ve Haklara Erişim Araştırması, https://derinyoksullukagi.org/wpcontent/uploads/2020/11/Pandemi-doneminde-derin-yoksulluk-ve-haklara-erisim-arastirmasiYerel-Yonetimlere-Kriz-Donemi-Sosyal-Destek.pdf Erişim Tarihi: 24.09.2021.

HUMPHREYS, K.L., MYINT, M.T. , ZEANAH, C.H. (2020). “Increased Risk For Family Violence During The COVID19 Pandemic", Pediatrics. https://publications.aap.org/pediatrics/article/146/1/e20200982/37027/Increased-Risk-forFamily-Violence-During-the?autologincheck=redirected Erişim Tarihi: 08.08.2021.

HYDE,Z. (2020). COVID-19, Children, and Schools : Overlooked and At Risk. Med J Aust 2020; 213(10), 444-446.

https://www.mja.com.au/system/files/issues/213_10/mja250823.pdf Erişim Tarihi: 10.08.2021.

İSTANBUL BAROSU ÇOCUK HAKLARI MERKEZİ, (2020). Pandemi Döneminde Çocuk Haklarını Koruma Mekanizmalarına Erişimde Yaşanan Sorunlar. https://www.istanbulbarosu.org.tr/HaberDetay.aspx?ID=15704\&Desc=\%C4\%B0stanbulBarosu-\%C3\%87ocuk-Haklar\%C4\%B1-Merkezinin--23-Nisan-2020-tarihliBas\%C4\%B1n-A\%C3\%A7\%C4\%B1klamas\%C4\%B1- (02.09.2021)

MílLî EĞİTiM BAKANLIĞI. (2020). Bakan Selçuk, Koronavirüs'e Karşı Eğitim Alanında Alınan Tedbirleri Açıkladı. https://www.meb.gov.tr/bakan-selcuk-koronaviruse-karsi-egitimalaninda-alinan-tedbirleri-acikladi/haber/20497/tr,web Erişim Tarihi: 01.09.2021. 
SIVILSAYFALAR (2020). Pandemiyle Birlikte Yeni Bir Aşamaya Geçen Çocuk Hakları Mücadelesi, https://www.sivilsayfalar.org/2020/11/20/pandemiyle-birlikte-yeni-bir-asamayagecen-cocuk-haklari-mucadelesi/ Erişim Tarihi: 20.09.2021.

TÜBA (2020). Covid-19 Pandemi Değerlendirme Raporu, http://www.tuba.gov.tr/files/images/2020/kovidraporu/Covid-19\%20Raporu-Final\%2B.pdf Erişim Tarihi: 01.06.2021.

UNICEF (2021). Covid-19 Salgınının Çocuklar Üzerindeki Etkileri, https://www.unicef.org/turkey/documents/covid-19-salg\%C4\%B1n\%C4\%B1n\%C4\%B1n\%C3\%A7ocuklar-\%C3\%BCzerindeki-etkileri Erişim Tarihi: 22.09.2021.

UNICEFTURK(2021a).https://www.unicefturk.org/public/uploads/files/UNICEF_CocukHaklari naDairSozlesme.pdf Erişim Tarihi: 23.07.2021.

UNICEFTURK(2021b).https://www.unicefturk.org/yazi/cocuklar-icinbilgi?gclid=EAIaIQobChMI0MDTooDH9AIVZbR3Ch1HNgeUEAAYASAAEgLjHPD_BwE Erişim Tarihi: 24.07.2021.

UNICEFTURK(2021c).https://www.unicefturk.org/yazi/cocuklar-icinbilgi?gclid=EAIaIQobChMIpL6RyqnG9AIVTOrtCh3IWwOhEAAYAiAAEgLYIfD_BwE Erişim Tarihi: 24.07.2021.

WANG, G., ZHANG, Y., ZHAO, J., ZHANG, J., JIANG, F. (2020). "Mitigate The Effects of Home Confinement on Children During The COVID-19 Outbreak", The Lancet, 395(10228), 945-947. https://www.thelancet.com/action/showPdf?pii=S01406736\%2820\%2930547-X Erişim Tarihi : 28.09.2021. 